\section{High-speed memory retrieval with auditorily presented stimuli*}

\author{
DONALD J. FOSS and BEN E. DOWELL † \\ University of Texas at Austin, Austin, Texas 78712
}

Two groups of $8 \mathrm{Ss}$ memorized three lists of consonental phonemes. The length of the memorized lists (M) was one, two, and four phonemes. Test words were presented, and reaction time (RT) for S to say whether or not the word started with a member of the memorized list was measured. RT increased with $M$. In one group, the phonemes comprising the memorized sets were dissimilar. RT increased linearly with $M$ for that group. In the other group, the phonemes comprising the sets were similar. The function relating $\mathrm{RT}$ to $\mathrm{M}$ appeared to deviate from linearity. Even after extended practice, all the evidence was consistent with a somewhat modified serial model of memory retrieval.

Recently, a number of experiments have followed up Sternberg's (1966) work on high-speed memory scanning. Sternberg varied the number of items Ss stored in memory (one, two, or four); he then visually presented a single item and measured Ss' reaction times (RT) to indicate whether or not the presented item was a member of the memorized set. He found a linear relationship between the number of items in the memorized set $(M)$ and $\mathrm{RT}$; the best fit equation was $\mathrm{RT}=$ $.369+.038(\mathrm{M})$. This result has been taken to indicate that Ss scanned their internal representation of the memorized set in a serial rather than a parallel manner, the scan rate being $38 \mathrm{msec} / \mathrm{item}$. Further work using similar techniques has permitted increasingly sophisticated analyses of the information processing stages that occur between the presentation of the test stimulus and S's response (e.g., Briggs \& Blaha, 1969; Nickerson, 1966; Sternberg, 1967, 1969a, b).

The present paper reports the results of an experiment which utilized the memory scanning technique but which presented the stimuli in the auditory mode and, in addition, manipulated the similarity of the members of the memorized sets. The experiment also tested the $\mathrm{Ss}$ for 5 successive days in order to observe the effects of practice on memory scanning in this situation.

The Ss were presented a list of words auditorily and were asked to push one button if the word started with a particular sound (phoneme), or one of a specified set of phonemes, and to push another button otherwise. The simtlarity of the nembers of the memorized set was manipulated in the following fashion: For one-half of the Ss, the members of the positive set shared a

*This study was supported by NSF-USDP Grant GU.1598 and by the NSF IIndergraduate Research Program.

+Now at the University of Minnesota. large number of phonological distinctive features ( see Halle, 1964a, b; Jenkins, Foss, \& Greenberg, 1968); in addition, the members of that set have been shown to be highly confusable in a discrimination task (Miller \& Nicely, 1955). In other words, the members of the memorized positive set were phonologically similar (sim group). For the other Ss, the members of the memorized set shared a minimal number of features (dis group).

It was thought that when the members of the positive set contained common features, the Ss might be able to respond to the test stimulus by asking if it possessed these relevant common features. That is, Ss in the sim group might (after practice) first analyze each test stimulus for the presence of the set of common features; then memory scanning could be done on the basis of these features of the stimuli rather than on the basis of the undecomposed stimuli (phonemes) themselves. (If a single subset of features could not exhaustively characterize the members of the positive set. the present argument could readily be gencralized to tases in which there were disjunctive subsets of features common to these members.) $\wedge$ similar analysis would not work for $S s$ in the dis group. Their menory search should be done on the basis of phonemes and nol features. Thus, when $M$ was, say, lour, the number of items in memory $t o$ be scanned could theoretically be reduced to, say, two for the sin group but could not be reduced for the dis group.

The above analysis implies that the slopes of the functions describing the search rates might differ between the sim and dis groups, the slopes for the former being less. In addition, the difference between the slopes for the two groups might be greater after extended practice at the task, since it would presumably lake some time for $S s$ in the sim group to discover and utilize the common features.

The slope data (for all conditions) might change (decrease) over days of the experiment for another reason: because Ss learn how to search their memory representation of the positive set stimuli in a parallel rather than a serial fashion. The parallel-serial issue remains somewhat clouded, despite a number of experimental attacks on it. Neisser $(1963,1967)$ found evidence in favor of a parallel search model in visual scanning tasks. Nickerson (1966) found no evidence for parallel scanning even after extended practice, but he changed the members of his positive set stimuli. Briggs and Blaha (1969) likewise reported evidence directly supporting the serial model after 12 experimental sessions. While the members of the positive set remained constant across the 12 sessions of their study, the stimuli were unfamiliar random figures. Perhaps evidence for parallel search will only show up after extended practice with extraordinarily overlearned and familiar stimulus materials. Those two conditions were met in the present study.

METHOD
Subjects
The Ss were 16 undergraduates (8/group) from the University of Texas at Austin. They were recruited by a posted advertisement and were paid a minimum of $\$ 1.50$ per session for the five sessions. They were tested in groups of four. In order to maintain motivation for highly accurate and fast responding, the $S$ in each group of each session who had the fastest average RT while maintaining at least $95 \%$ accuracy was paid a $\$ 1.00$ bonus.

\section{Materials}

Two sets of phonemes were chosen. In the sim group the phonemes in the memorized set (M) for $M=1,2,4$ were $/ \mathrm{b} /, / \mathrm{v}, \mathrm{L} /, / \mathrm{d}, \mathrm{g}, \mathrm{m}, \mathrm{n} /$, respectively. In the dis group the phonemes comprising these sets were $/ b / . / v, t /, / f, k, m, /$. The words in the positive set always began with one of these phonemcs. The words in the negative set (for both groups) began with $/ w, r, 1, j, p, y /$.

Lists of 40 words were constructed with 20 words beginning with a phoneme from the positive set and 20 beginning with a phonemc from the negative set. When $M=1$, all 20 positive-set words started with $/ b /$, and when $M=2$ or 4 , each member of the positive set occurred 10 or 5 times, respectively. A separate list of words was constructed for each of the five sets of positive stimuli (/b,va,dgmn,vt, $f \mathrm{~km} /$ /). The words were all one or two syllables long and all occurred at least three times/million in written English (Kucera \& Francis, 1967). Five randomizations of each list were prepared, one for cach of the five experimental sessions (days). 
Table 1

Mean Reaction Time (RT) in Milliseconds and Variance (VAR) for Each Experimental Condition (160 Observations/Point)

\begin{tabular}{|c|c|c|c|c|c|c|c|c|c|c|c|c|c|}
\hline \multirow{3}{*}{$\begin{array}{c}\text { Phoneme } \\
\text { SET }\end{array}$} & \multirow{3}{*}{$\begin{array}{c}\text { Memory } \\
\text { LOAD }\end{array}$} & \multicolumn{4}{|c|}{ Day 1} & \multicolumn{4}{|c|}{ Day 2} & \multicolumn{4}{|c|}{ Day 3} \\
\hline & & \multicolumn{2}{|c|}{ Yes } & \multicolumn{2}{|c|}{ No } & \multicolumn{2}{|c|}{ Yes } & \multicolumn{2}{|c|}{ No } & \multicolumn{2}{|c|}{ Yes } & \multicolumn{2}{|c|}{ No } \\
\hline & & RT & VAR & RT & VAR & RT & VAR & RT & VAR & RT & VAR & RT & VAR \\
\hline SIM & $\begin{array}{l}1 \\
2 \\
4\end{array}$ & $\begin{array}{l}416 \\
559 \\
612\end{array}$ & $\begin{array}{l}009 \\
032 \\
023\end{array}$ & $\begin{array}{l}503 \\
636 \\
688\end{array}$ & $\begin{array}{l}010 \\
026 \\
023\end{array}$ & $\begin{array}{l}454 \\
554 \\
638\end{array}$ & $\begin{array}{l}009 \\
039 \\
023\end{array}$ & $\begin{array}{l}537 \\
658 \\
600\end{array}$ & $\begin{array}{l}021 \\
021 \\
049\end{array}$ & $\begin{array}{l}469 \\
476 \\
626\end{array}$ & $\begin{array}{l}021 \\
041 \\
023\end{array}$ & $\begin{array}{l}529 \\
596 \\
569\end{array}$ & $\begin{array}{l}017 \\
023 \\
073\end{array}$ \\
\hline \multirow[t]{4}{*}{ DIS } & $\begin{array}{l}1 \\
2 \\
4\end{array}$ & $\begin{array}{l}559 \\
528 \\
615\end{array}$ & $\begin{array}{l}038 \\
016 \\
056\end{array}$ & $\begin{array}{l}614 \\
668 \\
777\end{array}$ & $\begin{array}{l}015 \\
020 \\
040\end{array}$ & $\begin{array}{l}467 \\
515 \\
696\end{array}$ & $\begin{array}{l}013 \\
018 \\
021\end{array}$ & $\begin{array}{l}534 \\
619 \\
658\end{array}$ & $\begin{array}{l}018 \\
013 \\
020\end{array}$ & $\begin{array}{l}388 \\
462 \\
588\end{array}$ & $\begin{array}{l}017 \\
023 \\
025\end{array}$ & $\begin{array}{l}437 \\
556 \\
635\end{array}$ & $\begin{array}{l}026 \\
026 \\
026\end{array}$ \\
\hline & & \multicolumn{4}{|c|}{ Day 4} & \multicolumn{4}{|c|}{ Day $5^{*}$} & \multicolumn{4}{|c|}{ End Check ** } \\
\hline & & \multicolumn{2}{|c|}{ Yes } & \multicolumn{2}{|c|}{ No } & \multicolumn{2}{|c|}{ Yes } & \multicolumn{2}{|c|}{ No } & & Yes & No & \\
\hline & & RT & VAR & RT & VAR & RT & VAR & RT & VAR & & RT & RT & \\
\hline SIM & $\begin{array}{l}1 \\
2 \\
4\end{array}$ & $\begin{array}{l}462 \\
523 \\
575\end{array}$ & $\begin{array}{l}082 \\
038 \\
019\end{array}$ & $\begin{array}{l}526 \\
650 \\
696\end{array}$ & $\begin{array}{l}015 \\
023 \\
040\end{array}$ & $\begin{array}{l}380 \\
511 \\
614\end{array}$ & $\begin{array}{l}015 \\
018 \\
019\end{array}$ & $\begin{array}{l}487 \\
570 \\
682\end{array}$ & $\begin{array}{l}015 \\
016 \\
029\end{array}$ & & $\begin{array}{l}472 \\
489 \\
619\end{array}$ & $\begin{array}{l}519 \\
631 \\
721\end{array}$ & \\
\hline DIS & $\begin{array}{l}1 \\
2 \\
4\end{array}$ & $\begin{array}{l}378 \\
440 \\
581\end{array}$ & $\begin{array}{l}013 \\
012 \\
018\end{array}$ & $\begin{array}{l}483 \\
536 \\
640\end{array}$ & $\begin{array}{l}017 \\
014 \\
021\end{array}$ & $\begin{array}{l}424 \\
477 \\
552\end{array}$ & $\begin{array}{l}011 \\
016 \\
019\end{array}$ & $\begin{array}{l}506 \\
522 \\
676\end{array}$ & $\begin{array}{l}021 \\
020 \\
028\end{array}$ & & $\begin{array}{l}511 \\
600 \\
650\end{array}$ & $\begin{array}{l}623 \\
691 \\
775\end{array}$ & \\
\hline
\end{tabular}

*Data for first session of Day 5; * Data for second session of Day 5.

In addition, five other lists of words (similarly constructed) were chosen for use at the end of the fifth session. That is, the words in these lists began with the same sets of positive and negative phonemes, but the words themselves differed from those used in the other daily lists. These stimuli were presented at the end of the study (end check test) to test whether the Ss had learned to operate on the basis of the critical phonemes or on the basis of the specific words presented. This would be critical if evidence in favor of parallel processing was emerging.

\section{Procedure}

On each day (except the fifth) the Ss were presented with six blocks of trials divided into two sessions of three blocks each. Each block consisted of a 40-word list as described above. The first block always had $M=1$, the second $M=2$, and the third $M=4$. After a 5- to 10-min rest break, these blocks were repeated in the same order. RT data were analyzed only for the second session of three blocks; the first sessions were considered to be warm-up and practice. On the fifth day the data from Session 1 were analyzed and are

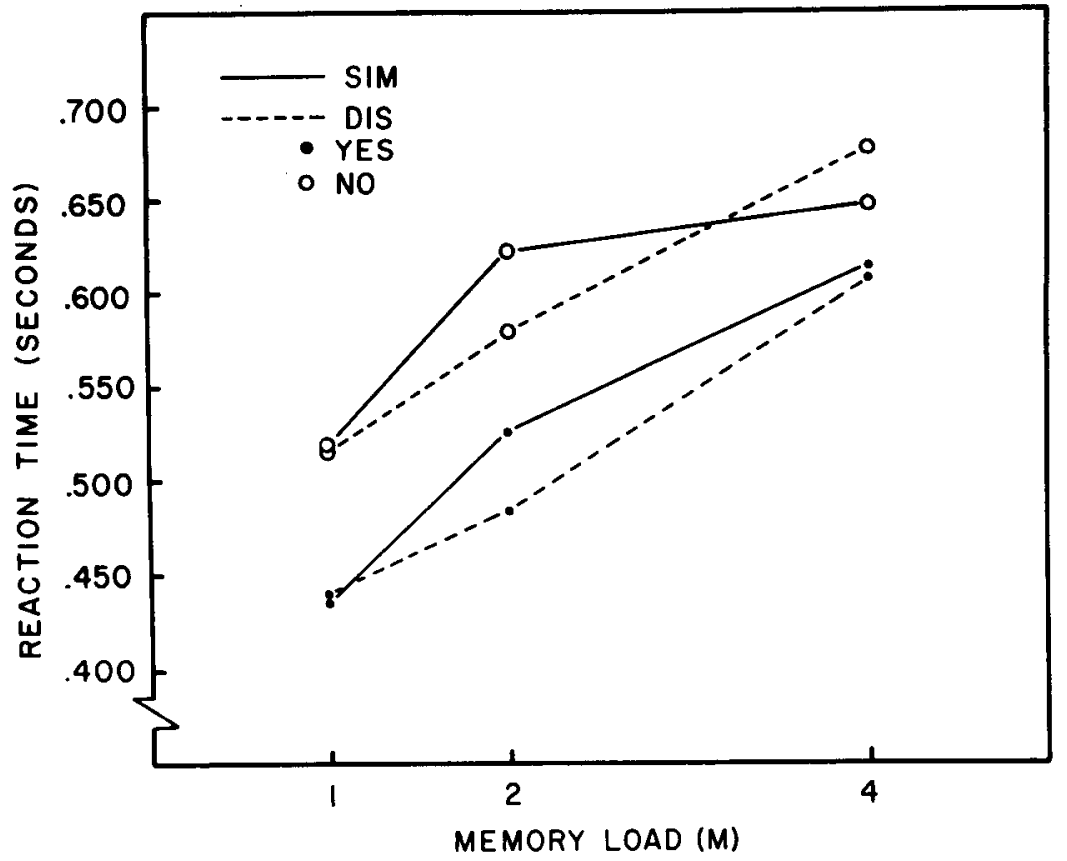

Fig. 1. Reaction time as a function of memory load (M), similarity of phoneme set, and response. reported here. The second session of Day 5 was devoted to the end check test.

The instructions and stimulus materials were presented on tape over headphones. A trial consisted of a $1,000-\mathrm{Hz}$ tone used as a ready signal, followed 2 sec later by the spoken stimulus word. The $\mathrm{S}$ pressed a response button with his right hand if the word started with a positive-set stimulus, the left button otherwise. A 5-sec interval occurred between the end of the word and the next ready signal. A timer was automatically started (by a signal recorded on another track of the tape) when each word occurred. The timing and response collection were under the control of a PDP 8/I computer. Timing was accurate to milliseconds; maximum trial duration was $2.5 \mathrm{sec}$. Although four Ss were run simultaneously, each was in a small booth and could not view the other Ss or $E$.

Thus, the experiment was a mixed factorial design with one between-S variable (sim vs dis sets of phonemes) and three within-S variables (three levels of memory load, 1, 2, 4; two responses, yes vs no; and five days). In addition, the end check test was presented at the fifth session.

\section{RESULTS}

Mean RTs were calculated for each group, condition, and session. These means, and their associated variances, are presented in Table 1. An analysis of variance performed on the RT data yielded the following patterns of results. First, there was no overall effect of similarity of phoneme set (sim vs dis), although there were significant main effects $(p<.01)$ for set size, day (RTs got faster over days), and the yes-no variable (yes responses were 
faster). However, the sim-dis variable did enter into two-way interactions with set size $(\mathrm{p}<.03)$ and day $(\mathrm{p}<.01)$ and a three-way interaction with set size and day $(p<.01)$. In addition, the set-size variable entered into a significant three-way interaction with the yes-no and day variables $(p<.02)$. No other interactions reached an acceptable level of significance (although the yes-no and day variables had $p<.08$ ). The overall pattern of the results is shown in Fig. 1. There it can be seen that yes responses were made considerably faster than no responses and that the lines for the sim conditions appear to deviate from linearity. (This is also shown by the significant interaction between sim-dis and set size.)

The linear least-squares equation was computed for the data of the dis group. For the yes responses RT = $.382+.055(\mathrm{M})$, while for the no responses $\mathrm{RT}=.466+.053(\mathrm{M})$. Obviously, most of the difference between these two equations is in the intercept parameter; the slopes are very nearly identical. While the data from the sim group appeared to deviate from linearity, the linear equations were computed for completeness. For the yes responses $\mathrm{RT}=.392+.057(\mathrm{M})$, while for the no responses RT $=.504+.039(\mathrm{M})$. Both the intercept and slope parameters differ markedly between these functions.

The data from each $\mathbf{S}$ in each condition and day were used to compute a linear least-squares RT equation. The slopes of the resulting equations were then subjected to an analysis of variance. The results of that analysis showed that the slopes were not significantly affected by the sim-dis, yes-no, or days variables. The latter is worth noting. The overall average slopes (memory scanning rates in seconds) across the five sessions were $.060, .058, .059$, .052 , and .060 . Since the slopes do not appear to be decreasing with practice, there is little evidence here in favor of parallel processing. The threc variables did, however, significantly interact $(p<.01)$.

The RT data from the end check test are also presented in Table 1. The RTs in this condition are elevated to approximately the level of the Day 1 data. As in the RT data from the rest of the study, the main effect for sim-dis was not significant, while the effect of set-size and the yes-no variable were both significant $(p<.01)$. While none of the two-way interactions were significant, the three-way interaction did reach significance $(p<.04)$.

The variance data given in Table 1 show a complex pattern of results. An analysis of variance was computed on these variance data. The most salient findings were two: First, all the variables entered into a significant four-way interaction $(p<.04)$ second, the overall effect for set size was significant $(p<.02)$. The overall average variances for $M=1,2$, and 4 were .020 , .023 , and .030 , respectively. Increases in variance with $M$ would seem to be consistent with a serial model of memory scanning.

Inspection of the variance data shown in Table 1 reveals one exception to the general increase of variance with $M$ : the yes responses in the sim group. The variances in the $M=4$ condition are less than in the $M=2$ condition in four of the five sessions; the fifth session is essentially a tie. This might be taken to support a parallel processing model, but another interpretation will be given below.

\section{DISCUSSION}

It is perhaps worth noting first that the results of the present study support the major findings of Sternberg (1966). Memory scanning is a serial and exhaustive process in situations like the present one. A number of basic differences exist between the previous memory scanning experiments and the present one, so the generality of Sternberg's finding is considerably extended. The previous experiments have used the visual mode; the present one used auditory presentation. The previous studies used single symbols; the Ss in the present study had to analyze the input word and segregate the initial phoneme for comparison with the memorized set. Thus, they dealt with longer strings of symbols.

The symbols used in the present study were highly familiar to Ss, and, in addition, the particular sets of symbols comprising the memorized positive sets were grcatly overlearned after 5 days of practice. Yet, even then, there was no general finding that was not perfectly consistent with a serial model of memory scanning.

The finding that differs from previous work (and is not immediately consistent with a serial model of memory scanning) concerns the apparent deviation of RT from linearity in the sim group (and also the variances of the yes responses in the $\operatorname{sim}$ group). But this result is consistent with the notion that $S s$ in that group treated the input stimuli somewhat differently. That is, they may have utilized the common features of the positive set to (1) direct their analysis of the input symbol and (2) recast their scan to take the features into account, rather than treating the phonemes as discretc unrelated symbols. This is to say that memory scanning is, to some extent, susceptible to strategies that may be devised to fit the circumstances. It is not, on the surface, contrary to the serial model.

Perhaps an analogy will help. Imagine that the symbols making up a positive set are all digits and that $S$ is presented with test items that are either digits or letters. When a test digit is presented, it is always a member of the positive set. In this case, it would not be surprising to see RT functions that deviated from linearity (or at least that had zero slopes), since Ss could learn to make use of the digit vs letter distinction to make their decision, independent of the number of digits in the positive set. While the stimuli in the sim group of the present study are not as homogeneous as a digit set in the above hypothetical experiment would be, it may be that an analogous process occurred. However, it must be noted that the data from the yes responses in the sim group did not decrease over days of the experiment (Table 1) as the present analysis predicts. These data were, in fact, quite variable. Thus, no firm conclusion concerning the feature analysis approach can be drawn. At a minimum, all that can be fairly said is that the information processing stages were affected by the similarity conditions.

The fact that the yes responses were made faster than the no responses replicates a common finding in this paradigm (e.g., Briggs \& Blaha, 1969). It is assumed that the difference between these response times is due to the response selection stage of information processing, but this difference has not yet been adequately explained.

The overall memory scanning rate is slower in this study (about $55 \mathrm{msec} / \mathrm{item}$ ) than in most of the previous studies using visual items $(35.40 \mathrm{mse} / \mathrm{item}$ is the common range). The slower rates observed in this study may be due to the fact that the symbol Ss had to decide about was the initial symbol of a word, whereas in the prior work only single test symbols had been presented. This line of reasoning seems unpromising, however, since the process of extracting the correct symbol from the input only has to happen once; thus, it should affect the intercept parameter of the RT function and not the slope. (Only processes that must increase with increasing memory load, such as comparing the presented stimulus with items in the positive set, are assumed to affect the slope parameter.) Another possibility for the scanning rate differences is that the auditory mode of presentation leads to slower scanning rates than the visual mode. If this were true, it would imply that the symbolic items with which $S$ was dealing retained some vestige of their input mode, i.e., that they were not abstract symbols. (See Sternberg, 1967, for a discussion of this issue and some other data bearing upon it.) A study which utilizes both modes of input within Ss might help illuminate this interesting issue. 


\section{REFERENCES}

BRIGGS, G. E., \& BLAHA, J. Memory retrieval and central comparison times in information processing. Journal of Experimental Psychology, 1969, 79, 395-402.

HALLE, M. Phonology in a generative grammar. In J. A. Fodor and J. J. Katz (Eds.), The structure of language: Readings in the philosophy of language, Englewood Cliffs, N.J: Prentice-Hall, 1964a.

HALLE, M. On the bases of phonology. In J. A Fodor and J. J. Katz (Eds.), The structure of language: Readings in the philosophy of languege. Englewood Cliffs, N.J: Prentice-Hall, $1964 \mathrm{~b}$.

JENKINS, J, J., FOSS, D. J., \& GREENBERG, J. $\mathrm{H}$. Phonological distinctive features as cues in learning. Journal of Experimental Psychology, $1968,77,200-205$.

KUCERA, H., \& FRANCIS, N. N. Computational analysis of present-day American English. Providence, R.1: Brown University Press, 1967. MILLER, G. A., \& NICELY, P. E. An analysis of perceptual confusions among some English consonants. Journal of the Acoustical Society of America, 1955, 27, 338-352.

NEISSER, U. Decision time without reaction time: Experiments in visual scanning. American Journal of Psychology, 1963, 76, 376-385.

NEISSER, U, Cognitive Psychology. New York: Appleton-Century-Crofts, 1967.

NICKERSON, R. S. Response times with a memory-dependent decision task. Journal of
Experimental Psychology, 1966, 72, 761-769. STERNBERG, S. High-speed scanning in human memory. Science, 1966, 153, 652-654.

STERNBERG, S. Two operations in character recognition: Some evidence from reaction-time measurements. Perception \& Psychophysics, $1967,2,45-53$

STERNBERG, S. The discovery of processing stages: Extensions of Donder's method. Acta Psychologica, 1969a, 30, 276-315.

STERNBERG, S. Memory-scanning: Mental processes revealed by reaction-time experiments. American Scientist, 1969b, 57, 421-457.

(Accepted for publication November 27, 1970.) 